\title{
A SSIMS and TPD Study of tert-Butylacetylacetate Adsorption on Si(100)
}

\author{
Che-Chen Chang,* Ing-Jye Huang, Chien-Hua Lung, Hsin-Yen Hwang, and Lu-Yu Teng \\ Department of Chemistry, National Taiwan University, 1 Roosevelt Rd., Sec. 4, Taipei, Taiwan, R.O.C. 10617
}

Received: July 26, 2000; In Final Form: October 13, 2000

\begin{abstract}
Adsorption and decomposition of tert-butylacetylacetate (tBAA) on $\mathrm{Si}(100)$ have been investigated using static secondary ion mass spectrometry and temperature-programmed desorption. At low doses, all tBAA molecules dissociate readily upon adsorption on the surface at temperatures as low as $-160{ }^{\circ} \mathrm{C}$. The dissociation may occur through tBAA bonding via the ester oxygen or the carbonyl group to the surface. The bond scission occurring at the $\mathrm{tBuO}-\mathrm{CO}$ bond leads to the formation of surface tert-butoxide. Further dehydrogenation can take place to yield isobutene and surface hydroxyl species. Subsequent heating of the substrate causes the hydroxyl to decompose, and the resulting substoichiometric silicon oxide sublimes as SiO. The surfaceinduced bond scission also occurs at the $\mathrm{OC}-\mathrm{CCO}$ bond of the tBAA diketo moiety to produce isobutene. In addition, the $\mathrm{OC}-\mathrm{CCO}$ bond scission induced by tBAA surface bonding, mainly via its carboxylic keto oxygen, affords acetaldehyde radical, whereas that induced mainly via the aceto oxygen yields carbon dioxide and isopropenoxy species. An enol-keto conversion takes place when isopropenoxy species acquire surface hydrogen to yield acetone, even at low substrate temperature of less than $-126^{\circ} \mathrm{C}$. The aceto oxygen pathway dominates the cleavage of the $\mathrm{OC}-\mathrm{CCO}$ bond. Increasing substrate temperature also causes the surface tertbutyl fragments to further react through different $\beta$-hydride elimination pathways, forming isobutene, which is either in the gaseous state or bound to the surface in a di- $\sigma$ configuration.
\end{abstract}

\section{Introduction}

As the feature sizes of the high-performance microelectronic devices shrink continuously in the submicron dimension, the chemical complexity involved in the formation of both the metastable and the final phases of device materials and in the diagnostics of surface and interface properties of these phases is dramatically increased. Resolving problems arising from this complexity rests to a large extent on a detailed understanding of the interaction between the chemical species in these phases and the substrate. In particular, understanding the interaction between a semiconductor and hydrocarbon is of great importance in view of the widespread use of chemical vapor deposition (CVD) in preparing thin films of various materials in the microelectronics industry. ${ }^{1,2}$ This interaction dictates the film growth, film and interface contamination, microstructure, and adhesion of these films.

Parallel to the shrinkage of feature sizes to $0.18 \mu \mathrm{m}$ and below in integrated circuit fabrication is the emergence of a class of complexes that may be employed as CVD precursors of copper. Copper has been replacing aluminum as the metal of choice in an attempt to reduce the problems related to the conductivity and the electromigration resistance of the contact material, although the corrosion (and the electromigration properties, as compared to that of tungsten) of copper thin films must be improved. ${ }^{3}$ The organic ligands chelated with copper in this class of complexes include various $\beta$-diketonate hydrocarbons, such as acetylacetonates (acac), ${ }^{4,5}$ hexafluoroacetylacetonates (hfac), ${ }^{6-11}$ trifluoroacetylacetonates (tfac), ${ }^{12}$ bisethylacetylacetonates (etac), ${ }^{13}$ and dipivaloylmethanates (dpm), ${ }^{14,15}$ These copper $\beta$-diketonate complexes appear to be superior precursors to $[\mathrm{Cu}(\mathrm{O}-\mathrm{tBu})]_{4},{ }^{16}$ $\mathrm{Cu}$ ("nona-F") ${ }_{2},{ }^{17}$ and (cyclopentadienyl)copper(I) phosphine, ${ }^{18,19}$

*Corresponding author. Fax: +2 23636359. E-mail: cchang@ ccms.ntu.edu.tw since the thermal decomposition of the latter compounds during copper film formation leads to impurity incorporation.

Among the copper $\beta$-diketonate precursors listed above, the acac and dpm complexes of copper have low deposition rates because of their insufficient volatility. ${ }^{4}$ Although some pure hfac or tfac complexes do yield copper films with high growth rates at low deposition temperature ${ }^{20-22}$ they are often unstable and difficult to handle. ${ }^{1,23}$ The use of $\mathrm{Cu}$ (hfac)tmvs (tmvs = vinyltrimethylsilane) as the precursor results in fluorine contamination, in addition to oxygen and carbon contamination, in the CVD copper matrix and at interfaces between films, with hfac being the contamination source. ${ }^{24,25}$ Recently, new $\beta$-diketonate precursors, such as bis(tert-butylacetoacetate)copper(II) ${ }^{26}$ and bis(ethylacetoacetate)copper(II), ${ }^{27}$ have been synthesized for the CVD of copper. By replacing the alkyl group on the carbonyl (such as in dpm) with the alkoxy group to form a $\beta$-keto ester as the ligand, these new copper precursors exhibited a high sublimation rate and a low pyrolysis temperature. ${ }^{28}$ The $\beta$-keto esters appear to alter the properties of the metal $\beta$-diketonate complex substantially, leading to an improvement of the precursor reactivity. ${ }^{13,28}$ Problems related to adhesion, via resistance, grain structure, and electromigration resistance due to fluorine contamination in the deposited film and interface are expected to be alleviated.

This possibility of tailoring the properties of precursors through subtle substitution in the ligand entices us in this study into investigating the interaction between tert-butylacetylacetate (tBAA) and the semiconductor surface for understanding the fundamental aspects of copper CVD from $\beta$-diketonate complexes. The tBAA has aceto and ester moieties, with the tertbutyl ester group $\beta$ to the carbonyl group. Most of the studies reported in the literature about the chemistry of ester adsorption on surfaces indicate that esters may adsorb molecularly on the surface to some extent. The adsorption of methyl formate has 
been studied on $\mathrm{Ni}(111)$ by Zahidi et al., ${ }^{29}$ on $\mathrm{Ag}(110)$ by Barteau et al., ${ }^{30}$ on $\mathrm{Ag}(111)$ by Schwaner et al., ${ }^{31,32}$ on Ni(111) by Zahidi et al., ${ }^{33}$ on $\mathrm{Cu}(110)$ by Sexton et al., ${ }^{34,35}$ on W(100) by Worley et al., ${ }^{36}$ of ethyl formate on $\mathrm{Ni}(111)$ by Zahidi et al., ${ }^{29,33}$ and of methyl acetate on $\mathrm{Ni}(111)$ by Zahidi et al. ${ }^{33}$ Results from these studies showed that small ester molecules can bond molecularly to the surface, with the orientation of the molecular symmetry plane nearly perpendicular to the surface. ${ }^{31-33}$ There are several stable configurations in which these small esters can bond to the surface. Vibrational spectroscopy suggested binding of these molecules involving lone pair donation from the carbonyl oxygen to the surface, ${ }^{33,34}$ with the carbonyl axis tilted from the surface plane. Depending on the rotameric form of the molecule, the interior $\mathrm{C}-\mathrm{O}$ bond of the ester linkage may be either nearly parallel to the surface, with the alkyl group pointing toward the substrate, ${ }^{31,32}$ or somewhat perpendicular to the surface, with the alkyl group slanting outward from the surface or parallel to the surface..$^{29,33}$

In addition, there are also a few studies focused on the surface reaction of molecules containing an aceto group $\beta$ to the keto group. Parmeter has used vibrational spectroscopy, thermal desorption measurements, and Auger spectroscopy to study the adsorption of hexafluoroacetylacetone $(\mathrm{hfacH})$ on $\mathrm{Pt}(111) .{ }^{37} \mathrm{His}$ results indicated the formation of a "lying-down" hfacH, adsorbed with its OCCCO skeleton essentially parallel to the surface. The adsorbed hfacH species showed significant decomposition below $300 \mathrm{~K}$ for any coverage conditions, with the decomposition products including $\mathrm{CO}$ and fluorine-containing fragments. Increasing the substrate temperature caused desorption of $\mathrm{CO}$ and $\mathrm{HF}$ near $430 \mathrm{~K}$, leaving two fluorocarbon species on the surface in significant concentration. On $\mathrm{Cu}(111)$ and $\mathrm{Cu}(100),{ }^{38}$ however, only "standing-up" hfacH was formed, which did not begin to decompose until about $375 \mathrm{~K}$. The adsorbed hfacH on these copper surfaces decomposed in a stepwise fashion to liberate fluorine, $\mathrm{CO}, \mathrm{CO}_{2}$, and fluorinated hydrocarbons. Furthermore, the reaction of hfacH on a stepped $\mathrm{Cu}(210)$ surface was reported to be fairly complete, with the formation of ten products desorbing in thirteen desorption states. $^{39}$

Growing thin films by CVD using precursors containing $\beta$-diketonates thus exhibits complex chemistry. Since the growth kinetics and the microstructure of the films are determined by the molecular structure of the CVD precursor, fundamental studies of the interaction between tBAA and the silicon surface may thus serve to reveal surface intermediates that are involved in the overall deposition mechanism of bis(tert-butylacetoacetate)copper(II). Studies on tBAA surface decomposition can also demonstrate plausible mechanisms by which such ligand decomposition leads to impurity incorporation into the growing copper films. Since the chemistry of tBAA molecules as well as the chemistry of other ligands having a molecular structure of an ester group $\beta$ to the carbonyl group are expected to be intimately related, the results obtained in this study are also of relevance to understanding the surface chemical mechanisms by which $\beta$-keto ester ligands fragment.

\section{Experimental Section}

All experiments are performed in a stainless steel ultrahigh vacuum chamber. The vacuum is maintained by a $220 \mathrm{~L} / \mathrm{s}$ ion pump and a titanium sublimation pump, after the chamber is initially evacuated by sorption and turbomolecular pumps. A base pressure of $1 \times 10^{-10}$ Torr can be achieved after baking out, the residual gas being mostly hydrogen. The working pressure is typically below $2.5 \times 10^{-10}$ Torr. This chamber is equipped with a quadrupole mass spectrometer (from Inficon), used for residual gas analysis and temperature-programmed desorption (TPD), another quadrupole mass spectrometer (from VG Microtech), used for static secondary ion mass spectrometry (SSIMS), a retarding field electron energy analyzer (from VG Microtech), used for both Auger electron spectroscopy (AES) and low-energy electron diffraction (LEED), and an ion gun (from VG Microtech). An electron impact ionizer is integrated to the Inficon mass spectrometer for detecting neutrals.

The Si(100) samples are acquired from International Wafer Service. They are antimony-doped $(\rho=0.0001-0.02 \Omega-\mathrm{cm})$ and are cleaved into approximately $10 \mathrm{~mm} \times 8 \mathrm{~mm} \times 0.5 \mathrm{~mm}$ rectangles from wafers. Prior to being placed under the vacuum, the samples are subjected to a wet-chemical cleaning process, ${ }^{40}$ including treatment of the surface with a HF solution for $1 \mathrm{~min}$ at room temperature followed by rinse with acetone and deionized water. This process produces a thin oxide layer that protects the underlayer silicon from further reaction. After the wet chemical treatment, two silicon samples are clipped together, back to back, with a thin tantalum sheet sandwiched in between. ${ }^{41}$ A pair of Chromel-Alumel thermocouples is spotwelded to the tantalum sheet for monitoring the sample temperature. For reference against the thermocouple, an optical pyrometer is used. The sandwiched silicon sample is then mounted to a manipulator using tantalum clamps. Once under ultrahigh vacuum, the protective oxide layer is removed by a slow annealing of $1-2 \mathrm{deg} / \mathrm{s}$ to $\sim 900{ }^{\circ} \mathrm{C}$, while maintaining the pressure below $3 \times 10^{-9}$ Torr, followed by a slow cooling to room temperature. In this work, sample heating to $950{ }^{\circ} \mathrm{C}$ is obtained by passing a high electrical current through the sample, whereas cooling to $-165^{\circ} \mathrm{C}$ is made possible by conduction from a nearby copper tank filled with liquid nitrogen. The $\mathrm{Si}(100)-2 \times 1$ surface is then generated by repeated cycles of Ar ion sputtering $\left(2 \mathrm{keV}, 0.7 \mu \mathrm{A}\right.$ beam current, $(1-2) \times 10^{-6}$ Torr, $30 \mathrm{~min}$ ) and annealing $\left(900^{\circ} \mathrm{C}, 2 \mathrm{~min}\right)$. Surface cleanliness and perfection of the sample are checked by AES, LEED, and SSIMS.

The tBAA is supplied by Acros and stored in a brown glass sample vial. It is further purified by several freeze-pumpthaw degassing cycles over zeolites prior to dosing. The purity of the tBAA vapor is checked in situ by mass spectrometry. To admit the reactant tBAA into the vacuum system, a variable leak valve is used. The tBAA is introduced onto the sample through background exposure. All doses reported in this study are in langmuirs $\left(1 \mathrm{~L}=1 \times 10^{-6}\right.$ Torr-s) of exposure at the sample surface. The exposure pressure is measured with an ionization gauge and is kept below $3 \times 10^{-9}$ Torr. The reading of the gauge is uncorrected for the corresponding sensitivity.

TPD experiments are conducted with the sample in line-ofsight of the mass spectrometer (nondifferentially pumped). To preferentially admit gases desorbing directly from the sample surface to the ionizer, this spectrometer is fitted with a stainless steel skimmer with a $0.3 \mathrm{~cm}$ diameter opening. For TPD measurements, the sample is placed $\sim 0.1$ in. away from the skimmer. Measurements of the intensities of desorbing species are controlled by interfacing the spectrometer control unit to a personal computer. During each TPD measurement, a linear temperature ramp is applied to the sample and the spectrometer is set to monitor several masses. A heating rate of $3{ }^{\circ} \mathrm{C} / \mathrm{s}$ is used in all TPD experiments.

SSIMS measurements are performed with the sample also in line-of-sight of the mass spectrometer (nondifferentially pumped). A primary beam of Ar ions of $2 \mathrm{keV}$ energy is used to bombard the sample, with the impact angle measured from the surface 


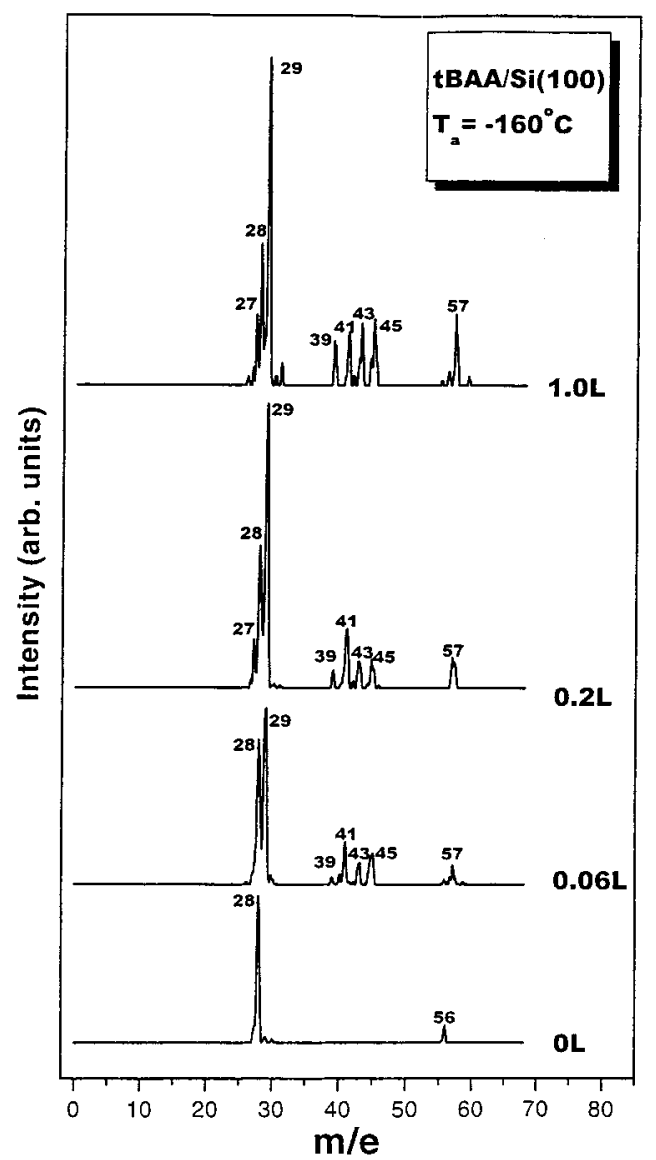

Figure 1. Secondary ion mass spectrum of a $\mathrm{Si}(100)$ surface exposed to the indicated doses of tBAA. All spectra are recorded at $-160{ }^{\circ} \mathrm{C}$. The spectra have been normalized to a constant peak height at $m / e 28$.

fixed at 45 degrees. The ion gun is differentially pumped and operated at a pressure of $3 \times 10^{-9}$ Torr when SSIMS spectra are recorded. With respect to the large cross section for sputter desorption and damaging, total ion currents are held within the $(1-3) \times 10^{-9}$ Amp range and the beam diameter is controlled to about $15 \mathrm{~mm}^{2}$. A bias voltage of $22 \mathrm{~V}$ is applied to the sample to increase measured yield of secondary ions. Data collection is accomplished using an interface system designed by VG Microtech. The typical data collection time is $<10 \mathrm{~min} /$ spectrum. No correction of the spectra for background is made.

\section{Results}

The low-temperature adsorption behavior of tBAA on the $\mathrm{Si}(100)$ surface is initially studied by secondary ion mass spectrometry. The surface temperature for these adsorption experiments is $-160{ }^{\circ} \mathrm{C}$. Figure 1 displays the SSIMS spectra taken by exposing a clean $\mathrm{Si}(100)$ sample to several different doses of tBAA. A typical SSIMS spectrum taken from a clean $\mathrm{Si}(100)$ surface shows peaks at $m / e$ 28, 29, 30, and 56. The $m / e$ peaks of 28,29 , and 30 result from the sputter desorption of $\mathrm{Si}^{+}$isotopes from the surface. The m/e 56 peak contains a contribution from the sputter desorption of $\mathrm{Si}_{2}{ }^{+}$.

At low doses of less than $0.2 \mathrm{~L}$, tBAA decomposes readily on the $\mathrm{Si}(100)$ sample even at low substrate temperature. As shown in Figure 1, a number of m/e peaks at 28, 29, 41, 43, 45 , and 57 can be identified in the SSIMS spectrum taken after the $\mathrm{Si}(100)$ surface is exposed to $0.06 \mathrm{~L}$ of tBAA at $-160{ }^{\circ} \mathrm{C}$. No parent peak of tBAA $(m / e 158)$ is observed in the spectrum. In fact, there is no noticeable signal present in the spectrum

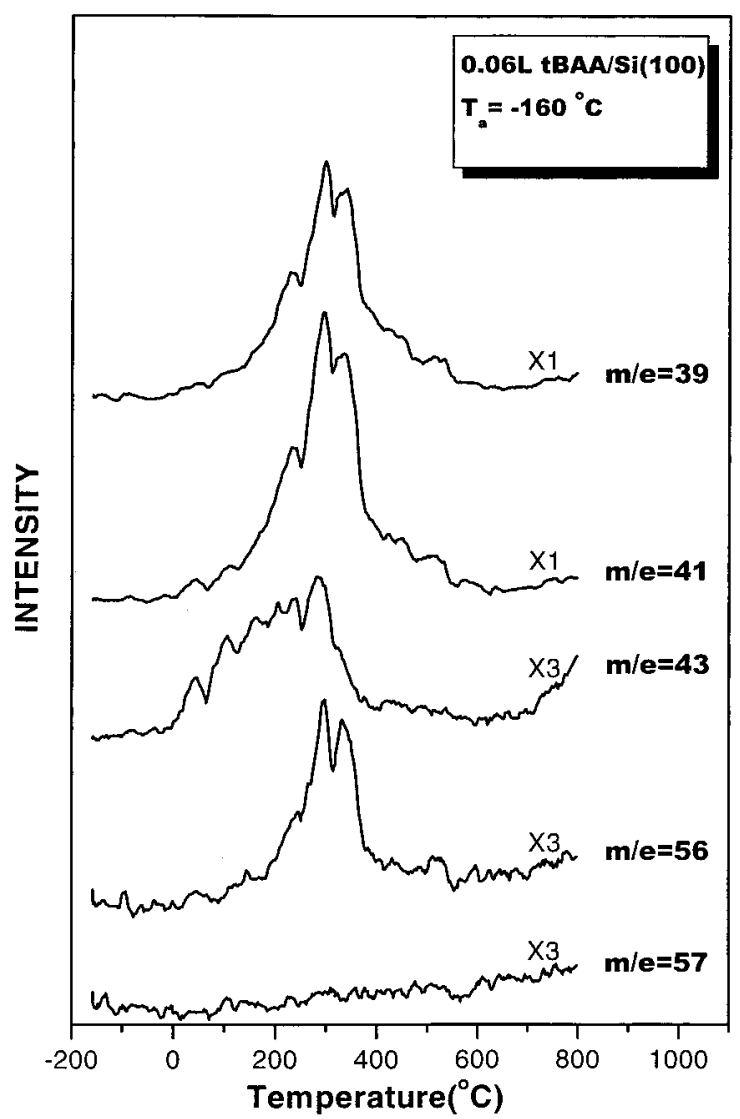

Figure 2. TPD profiles for a $0.06 \mathrm{~L}$ dose of tBAA on $\mathrm{Si}(100)$ at $-160{ }^{\circ} \mathrm{C}$. The profiles are taken at indicated $\mathrm{m} / \mathrm{e}$ and the heating rate is $3{ }^{\circ} \mathrm{C} / \mathrm{s}$.

with $m / e$ of higher than 57. According to the sputtering theory, ${ }^{42}$ the secondary ions ejecting from the sample may originate from the positions located a few tens of angstroms away from the point of impact where the ion-induced fragmentation of adsorbates may take place. Ion ejection from these far-away positions is brought about by momentum transferred late in the collision cascade from underneath atoms that move upward. These atoms usually have kinetic energies too low to cause dissociative emission of adsorbates. ${ }^{43}$ Molecular ions of noticeable intensity may thus be detected when the current density and the total dose of the primary ion are minimized. ${ }^{44}$ The absence of the tBAA molecular peak in Figure 1 thus reveals that tBAA may all decompose on the $\mathrm{Si}(100)$ surface at -160 ${ }^{\circ} \mathrm{C}$ upon adsorption. TPD data and mass spectral analyses of molecular tBAA are also consistent with the SSIMS results.

Fragments produced from the low-temperature decomposition of tBAA on $\mathrm{Si}(100)$ may be identified with the aid of TPD studies. They may react further on the sample surface and desorb at increasing substrate temperatures. Presented in Figure 2 are TPD spectra taken from the $\mathrm{Si}(100)$ surface exposed to tBAA at $-160{ }^{\circ} \mathrm{C}$. These experiments are performed with an electron impact device placed in front of the quadrupole mass analyzer for ionizing particles which thermally desorb from the sample surface. The reaction products monitored in these TPD experiments include those with $m / e=39,41,43,56$, and 57. At 0.06 $\mathrm{L} \mathrm{tBAA}$ exposure, m/e 56 is observed to desorb in the substrate temperature range between 150 and $400{ }^{\circ} \mathrm{C}$. In addition, the TPD profiles obtained at m/e 39 and 41 resemble closely the one obtained at $m / e 56$, indicating that the $m / e 39$ and 41 species are fragments in the TPD ionizer of the one with m/e of 56. The ratios of the integrated areas of the TPD peaks, in which 


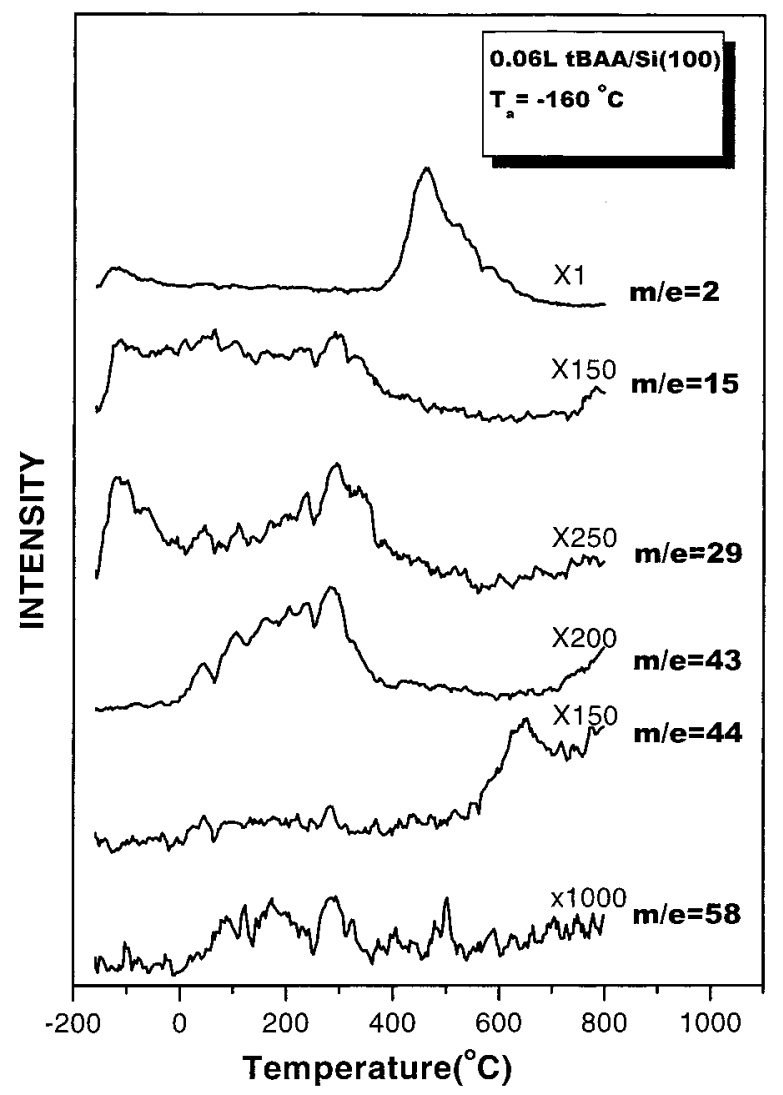

Figure 3. TPD profiles for a $0.06 \mathrm{~L}$ dose of tBAA on $\mathrm{Si}(100)$ at $-160{ }^{\circ} \mathrm{C}$. The profiles are taken at indicated $\mathrm{m} / \mathrm{e}$ and the heating rate is $3{ }^{\circ} \mathrm{C} / \mathrm{s}$. The $m / e 43$ spectrum shown in Figure 2 is redisplayed here for better identifying the fragmentation pattern of acetone.

$\operatorname{area}_{41}>\operatorname{area}_{39}>\operatorname{area}_{56}$, are close to the reported ratios ${ }^{45}$ of the signals in the electron-impact mass spectrum of isobutene. The resemblance of these TPD profiles and the similarity of the peak ratios to those of the reported spectrum suggest that isobutene $(m / e=56)$ is produced after tBAA molecules decompose on the $\mathrm{Si}(100)$ surface. It is noted that the absence of TPD peaks in the m/e 57 spectrum indicates no tBAA molecules present on the surface, because the electron-impact fragmentation pattern ${ }^{45}$ of tBAA predicts a high signal intensity in the mass spectrum from the m/e 57 fragment if tBAA molecules were desorbed.

A noticeable amount of acetone is also formed on the surface after tBAA is decomposed on $\operatorname{Si}(100)$. Figures 3 and 4 show TPD spectra measured with the mass analyzer tuned to the indicated $m / e$ values following tBAA exposures of 0.06 and $1.0 \mathrm{~L}$, respectively, to $\mathrm{Si}(100)$ at $-160{ }^{\circ} \mathrm{C}$. Acetone has a base peak at $m / e$ 43, along with other main peaks at m/e 58 and 15 in its electron-impact mass spectrum. ${ }^{45}$ The TPD profiles of $m / e$ 58, 43, and 15 displayed in Figures 3 and 4 are consistent with the fragmentation pattern for acetone.

Hydroxyl groups are also present on the $\mathrm{Si}(100)$ surface when tBAA is decomposed. The production of surface hydroxyl can be confirmed by increasing the substrate temperature such that the hydroxyl further reacts with the surface to form a substoichiometric silicon oxide, probably in a bridge-bonded oxygen arrangement $(\mathrm{Si}-\mathrm{O}-\mathrm{Si}) .{ }^{46}$ The gasification of this oxide to form $\mathrm{SiO}(\mathrm{g})$ will result in a desorption feature in the $m / e 44$ TPD spectrum, as shown in Figure 3, at substrate temperatures above $600{ }^{\circ} \mathrm{C} .47$

In circumstances where more oxygen is available for forming subsurface oxide such that there is greater oxygen coordination

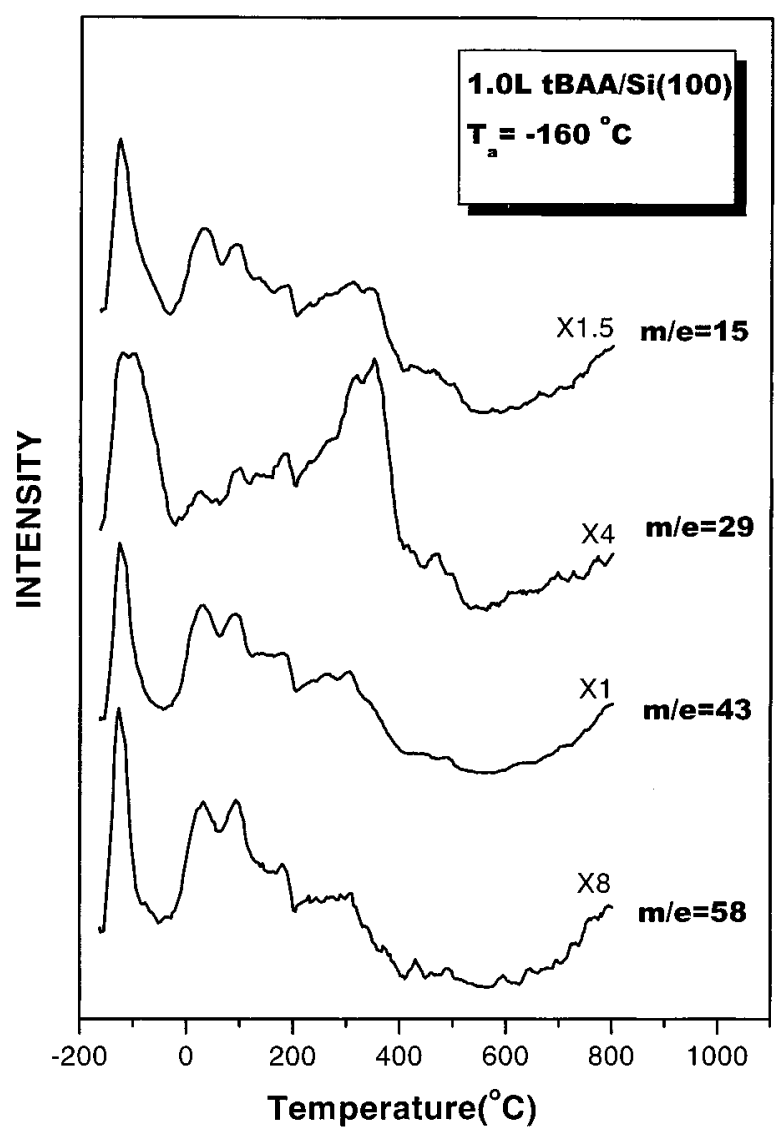

Figure 4. TPD profiles for a $1.0 \mathrm{~L}$ dose of tBAA on $\mathrm{Si}(100)$ at $-160{ }^{\circ} \mathrm{C}$. The profiles are taken at indicated $m / e$ and the heating rate is $3{ }^{\circ} \mathrm{C} / \mathrm{s}$.

for each $\mathrm{Si}$ atom, the silicon oxide becomes stable to higher substrate temperature. ${ }^{48}$ The higher thermal stability should cause the observed desorption maximum in the m/e 44 TPD profile to shift to higher temperatures, if the desorption indeed comes from the sublimation of $\mathrm{SiO}$. Figure 5 presents the TPD profiles obtained from the $\mathrm{Si}(100)$ surface which is exposed to the indicated doses of tBAA. As shown in the figure, the desorption maximum above $600{ }^{\circ} \mathrm{C}$ shifts to higher substrate temperatures as the tBAA dose is increased. A shift of about $25^{\circ} \mathrm{C}$ is observed as the dose is increased from 0.06 to $1.0 \mathrm{~L}$. The desorption feature observed in the m/e 44 TPD spectra above $600{ }^{\circ} \mathrm{C}$ thus reveals the presence of surface hydroxyl on $\mathrm{Si}(100)$ after tBAA is decomposed.

\section{Discussion}

The decomposition of all tBAA molecules at low exposure on the clean $\mathrm{Si}(100)$ surface at $-160{ }^{\circ} \mathrm{C}$ is quite interesting, because, as discussed in the Introduction section, many ester molecules can adsorb molecularly on the solid surfaces at low temperature. ${ }^{31-36}$ The decomposition is not due to the ionbombardment-induced fragmentation during SSIMS measurements, as a pilot SSIMS spectrum taken with data collection time of $30 \mathrm{~s}$ from the sample surface exposed to $0.06 \mathrm{~L} \mathrm{tBAA}$ shows an intensity distribution similar to the one shown in Figure 1, although the signal/noise ratio is poor. The absence of tBAA in the molecular state when adsorbed on the silicon surface at $-160{ }^{\circ} \mathrm{C}$ may be accounted for in part by steric considerations. As an oxygenate, tBAA may bond to the sample surface via the ester group ${ }^{49}$ (Figures 5a and 5b). In addition, depending on the molecular orientation of tBAA relative to the 


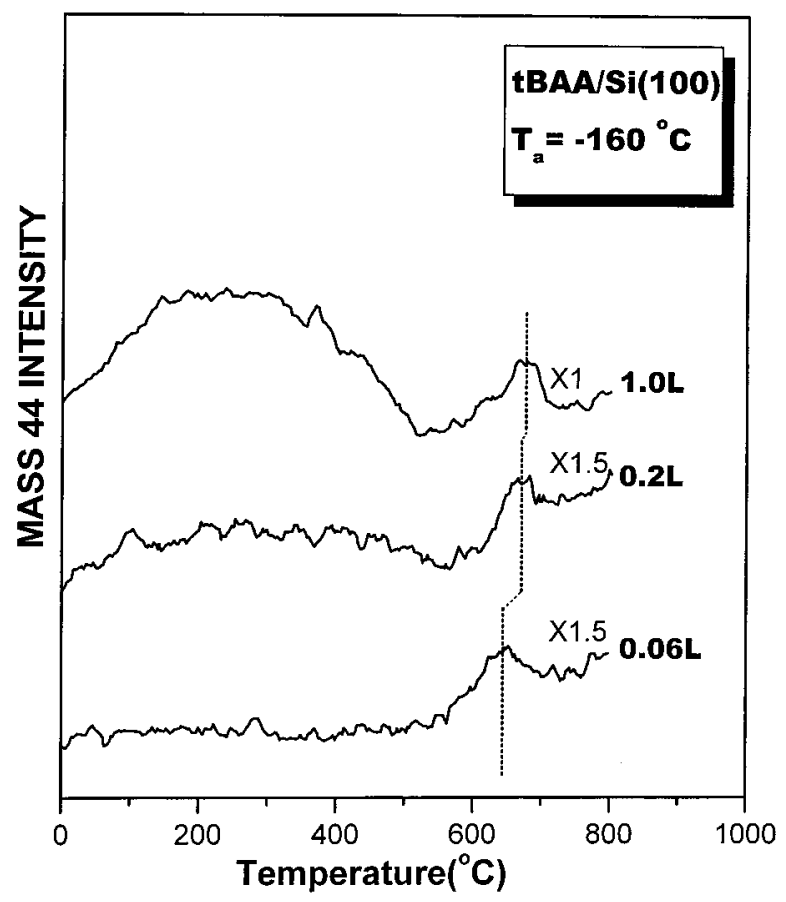

Figure 5. TPD profiles for the $m / e 44$ species desorbing from $\mathrm{Si}(100)$ after various exposures of tBAA at $-160{ }^{\circ} \mathrm{C}$. The heating rate is $3{ }^{\circ} \mathrm{C} / \mathrm{s}$. The $\mathrm{m} / \mathrm{e} 44$ spectrum shown in Figure 3 is rescaled here for better comparison.

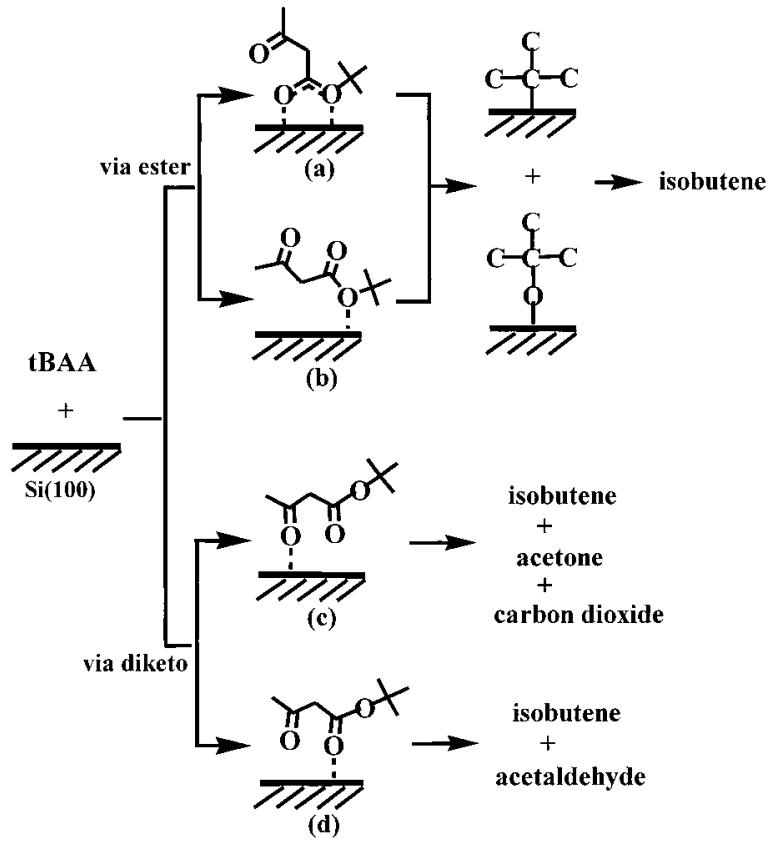

Figure 6. Illustration of possible decomposition pathways of tBAA on $\operatorname{Si}(100)$.

surface at the time of adsorption, the diketo moiety of tBAA may also bond to the surface directly (Figures $5 \mathrm{c}$ and $5 \mathrm{~d}$ ). In either bonding configuration, the surface would be active for the rupture of chemical bonds, as discussed below.

4.1. tBAA Decomposition via Ester Bonding. For tBAA to bond via the ester oxygen with (a $\eta^{3}$ configuration, Figure 6a) or without (a $\eta^{1}$ configuration, Figure $6 \mathrm{~b}$ ) the involvement of the ester carbonyl group, the surface may induce a bond scission at either the $\mathrm{tBu}-\mathrm{O}$ bond or the $\mathrm{tBuO}-\mathrm{CO}$ bond. The scission of the $\mathrm{tBu}-\mathrm{O}$ bond produces tert-butyl fragment $(m / e=57)$ on the surface, which gives rise to the m/e 57 peak in the SSIMS spectrum (Figure 1). It is known that bond cleavage is favored at the alkyl-substituted carbon atoms. The more a carbon atom is substituted, the more likely it is to be cleaved. The unique stability of tert-butyl fragments may thus facilitate the decomposition of tBAA molecules on the surface.

In addition, a bond cleavage at the $\mathrm{tBuO}-\mathrm{CO}$ bond of $\mathrm{tBAA}$ may also be induced on the surface. The cleavage of the $\mathrm{tBuO}-$ $\mathrm{CO}$ bond may result in the formation of the $\mathrm{tBuO}-\mathrm{Si}$ bond on the surface. The data obtained in this study do not shed light on the identity of the $\mathrm{Si}(100)$ adsorption site ${ }^{50}$ to which $\mathrm{tBuO}$ prefers to bond, although a synchrotron radiation photoemission study of ethanol on $\mathrm{Si}(100)^{51}$ has ascertained a preferential dissociative chemisorption of ethanol on the surface dimers because of their distinct reactivity due to the buckled nature. It is also noteworthy that the preferred adsorption site can vary with the size of the alkyl group. Synchrotron radiation photoemission $^{52,53}$ and photostimulated desorption ${ }^{53}$ studies of alcohol adsorption on $\mathrm{Si}(111)$ have shown that adsorption of the alkoxy species on the rest atom sites becomes less favorable as the size of the alkyl group is increased.

4.1.1. Isobutene vs Isobutane. Following the bond scission which occurs through binding of tBAA via the ester group, the surface reaction may proceed further. Two reaction products are most likely to be formed on the surface at $-160{ }^{\circ} \mathrm{C}$. One product is isobutane, which is formed by attaching a surface hydrogen to the tert-butyl fragment. The major m/e peaks appearing in the reported electron-impact mass spectrum of isobutane usually include 43,41, 42, 27, and 39 (in order of decreasing signal intensity ${ }^{45}$ ). The other product is isobutene, which may be formed by eliminating a hydrogen from the tertbutyl surface fragment or from the $\mathrm{tBuO}-\mathrm{Si}$ surface species. Isobutene has a fragmentation pattern with the major $m / e$ peaks in the electron-impact mass spectrum at 41, 39, 56, 28, and 27 (in order of decreasing signal intensity ${ }^{45}$ ). Although the ionization process employed to obtain spectra shown in Figure 1 is different from the electron-impact process, the ratios of the integrated areas of the SSIMS peaks obtained following a 0.06 $\mathrm{L}$ dose of tBAA at $-160{ }^{\circ} \mathrm{C}$ seem to be more consistent with the fragmentation pattern for isobutene.

The presence of isobutene on the surface due to tBAA decomposition upon adsorption is also supported by results from TPD experiments. As presented in Figure 2, the TPD profiles (and their peak ratios) taken at $m / e ~ 56,41$, and 39 suggest that isobutene is the major product present on the $\mathrm{Si}(100)$ surface after tBAA decomposition. The electron-impact fragmentation pattern ${ }^{45}$ for isobutane predicts an observation of the highest signal intensity in the mass spectrum from the m/e 43 fragment and the second highest from the $m / e 41$ fragment, if isobutane, instead of isobutene, were the major decomposition product of tBAA on the surface. Figure 2, however, shows the opposite. The large difference in the $m / e$ and $m / e 43$ TPD profiles also excludes the possibility that isobutane is the major product of the surface reaction that occurs following the surface-induced bond scission of tBAA. Results of this study, however, cannot leave out the possibility that small amounts of isobutane may also be produced from the surface decomposition of tBAA.

4.1.2. Surface Alkyl Reaction Pathway. There are two different groups of surface reaction pathways that may account for the observed production of isobutene. One is via elimination of a hydrogen from the surface alkyl fragment, the other from the alkoxy species. The elimination of hydrogen from the alkyl species on the surface to yield alkene has been reported in the literature. Studies using high-resolution electron energy loss spectroscopy and X-ray photoelectron spectroscopy about the 
adsorption chemistry of tertiarybutylphosphine on $\mathrm{Si}(100)$ have shown that tertiarybutylphosphine can be partially decomposed on the surface at room temperature. ${ }^{54}$ Increasing the substrate temperature would then cause butene to evolve, with a broad $m / e 56$ peak in the TPD spectrum between 100 and $400{ }^{\circ} \mathrm{C}$. No TPD peaks were found for the $\mathrm{C}_{4} \mathrm{H}_{9}{ }^{+}$spectrum $(m / e=57)$ up to $650{ }^{\circ} \mathrm{C}$. The peak temperature range for $m / e 56$ and the absence of the $m / e 57$ peak are consistent with our observations (Figure 2). Based on Fourier transform infrared-attenuated total reflection (FTIR-ATR) and TPD studies of the reaction of tertbutyl silane on $\mathrm{Si}(100)$, E. Rudkevich et al. also concluded the presence of isobutene on the surface, after bond cleavage first took place at the $\mathrm{Si}-\mathrm{C}$ bond to form tert-butyl species. ${ }^{55}$ These reports reveal that the production of alkene on the $\mathrm{Si}(100)$ surface does not have to go through the alkoxy reaction pathway, because in either case no surface alkoxy intermediates can be generated. Dehydrogenation of the alkyl group on the $\mathrm{Si}(100)$ surface to form alkene has also been reported for decomposition fragments generated from diethylzinc, ${ }^{56}$ diethylsilane, ${ }^{57,58} \mathrm{di}$ ethylgermane, ${ }^{59}$ triethylphosphine,${ }^{54}$ triethylgallium, ${ }^{60}$ and trisisobutylaluminum. ${ }^{61}$ Similar alkene formation processes from alkyl fragments also occur on other surfaces. ${ }^{61,62}$

4.1.2.1. $\alpha$-Hydride Elimination. The decomposition of surface alkyl groups to form their alkene counterparts may proceed through either an $\alpha$-hydride ${ }^{63}$ or a $\beta$-hydride elimination step. ${ }^{64}$ The former mechanism involves abstraction of $\alpha$-hydrogen from the adsorbed alkyl fragment, followed by a 1-2 hydride shift to yield alkene. It usually takes place as a minor reaction pathway for the decomposition of alkyl groups on the surface, ${ }^{64}$ except when methyl groups are present. ${ }^{65,66}$ In the latter case, $\alpha$-hydride elimination reactions seem to be the most logical pathway for the observed chemistry. However, in this study tBAA does not undergo surface decomposition through the 1-2 hydride shift because of the absence of $\alpha$-hydrogen.

4.1.2.2. $\beta$-Hydride Elimination. The $\beta$-hydride elimination proceeds when the adsorbed alkyl species deposits a hydrogen from the $\beta$ carbon atom onto the surface to form surface hydride and alkene. This decomposition mechanism has been verified in FTIR annealing studies ${ }^{63}$ based on a characteristic increase, associated with the $\beta$-hydride elimination reaction, in the intensity of the surface hydride symmetric stretch vibration with the formation of alkene. For the tBAA decomposition reaction involving tert-butyl fragments on $\operatorname{Si}(100)$, there may be three $\beta$-hydride elimination pathways to yield isobutene. The first pathway involves the abstraction, by an adjacent silicon dangling bond, of $\beta$-hydrogen to form surface hydride (Figure 7a). The second takes place when the eliminated hydrogen is deposited, possibly through a four-membered-ring intermediate, onto the $\mathrm{Si}$ atom on which the tert-butyl fragment is bound (Figure $7 \mathrm{~b}$ ). Both of these mechanisms lead to the formation of gaseous isobutene, allowing a clean removal of the alkyl groups in the ligand of a CVD precursor. ${ }^{54,57,59,60}$ The observation of some carbon incorporation into the substrate when trisisobutylaluminum $^{61}$ and tert-butyl silane ${ }^{55}$ decompose on $\mathrm{Si}(100)$, however, reveals the possible existence of the third $\beta$-hydride elimination pathway for the tBAA surface decomposition involving tertbutyl fragments. With this mechanism, a nearby dangling bond of the substrate atom abstracts a $\beta$-hydrogen of the surface tertbutyl species, while the carbon atom originally bound to this hydrogen is trapped by another neighbor dangling bond (Figure 7c). This reaction mechanism leads to the formation of alkene which is bound to the surface in a di- $\sigma$ configuration. ${ }^{56,58}$ The production of the adsorbed alkene from the alkyl group undergoing $\beta$-hydride elimination is also observed for the

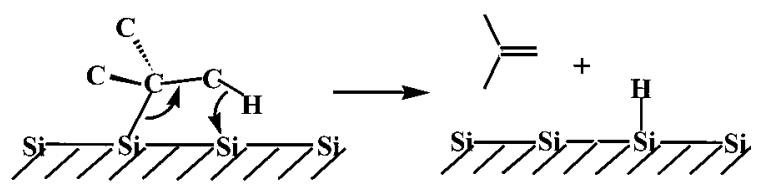

(a)

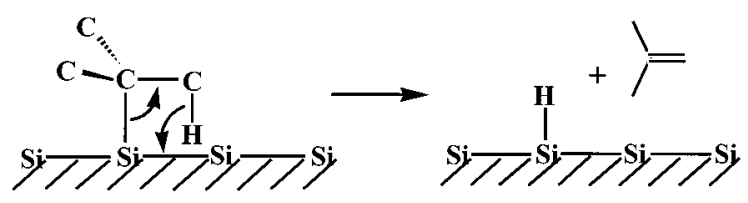

(b)

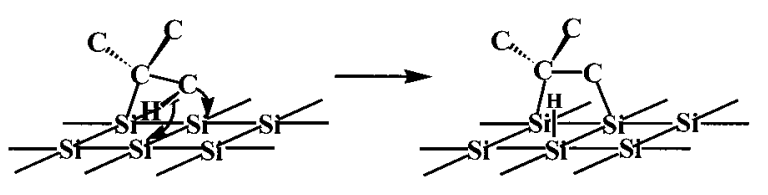

(c)

Figure 7. Proposed mechanism by which tert-butyl fragments from tBAA produce (a) and (b) isobutene molecules and (c) surface isobutene in a di- $\sigma$ configuration, respectively.

decomposition of diethylsilane on $\mathrm{Si}(100)$ and $\mathrm{Si}(111)^{58}$ and of diethylzinc on $\mathrm{Si}(100) .{ }^{56}$

Deuterium labeling of the alkyl group has provided direct evidence that the $\beta$-hydride elimination step is the predominant pathway to alkene production from the alkyl fragments on the surface. ${ }^{64}$ However, in this study, the $\beta$-hydride elimination pathway may not be the predominant reaction process responsible for the observed production of isobutene on $\mathrm{Si}(100)$ at $-160{ }^{\circ} \mathrm{C}$. Although the $\beta$-hydride elimination reaction of alkyl groups on $\mathrm{Si}(100)$ can be viewed as a concerted process,${ }^{57}$ in which the cleavage of the $\mathrm{Si}-\mathrm{C}$ bond, the cleavage of the $\beta$ $\mathrm{C}-\mathrm{H}$ bond, the alkene bond formation, and the formation of surface $\mathrm{Si}-\mathrm{H}$ may take place at the same time, it is known that the rate determining step in this reaction is the abstraction of the $\beta$-hydrogen atom onto the surface. ${ }^{62}$ The gas phase $\beta$-hydride elimination reaction is found to be endothermic by $\sim 21 \mathrm{kcal} / \mathrm{mol} .{ }^{67}$ The activation energy for $\beta$-hydride elimination occurring on the surface was believed to be higher than this value. ${ }^{61,62}$ The conversion of the surface alkyl species to alkene through such an endothermic hydride elimination process thus is too slow at the substrate temperature of $-160{ }^{\circ} \mathrm{C}$ to be significant. ${ }^{54-62}$ In other words, the observed low-temperature decomposition of tBAA to produce isobutene on $\mathrm{Si}(100)$ cannot be attributed mainly to the tert-butyl fragments undergoing $\beta$-hydride elimination on the surface. The $\beta$-hydride elimination pathway of the surface alkyl species is not the main source for the observed isobutene signals in the SSIMS spectrum (Figure 1) for low doses of tBAA on $\mathrm{Si}(100)$. However, in TPD experiments, the endothermicity of the $\beta$-hydride elimination reaction is overcome by enthalpy increases. The surface reaction through $\beta$-hydride elimination may thus contribute to the observed multi-peak profiles between 150 and $400{ }^{\circ} \mathrm{C}$ of the TPD spectra (Figure 2) taken at m/e 56, 41, and 39.

4.1.3. Surface Alkoxy Reaction Pathway. An alternative pathway for yielding isobutene on the surface at $-160{ }^{\circ} \mathrm{C}$ is through decomposition of the $\mathrm{tBuO}$ species, which is formed through the surface-induced cleavage of the $\mathrm{tBuO}-\mathrm{CO}$ bond of tBAA. Early studies about the reactivity of alkoxy species, which were generated via deprotonation of the $\mathrm{OH}$ group of 


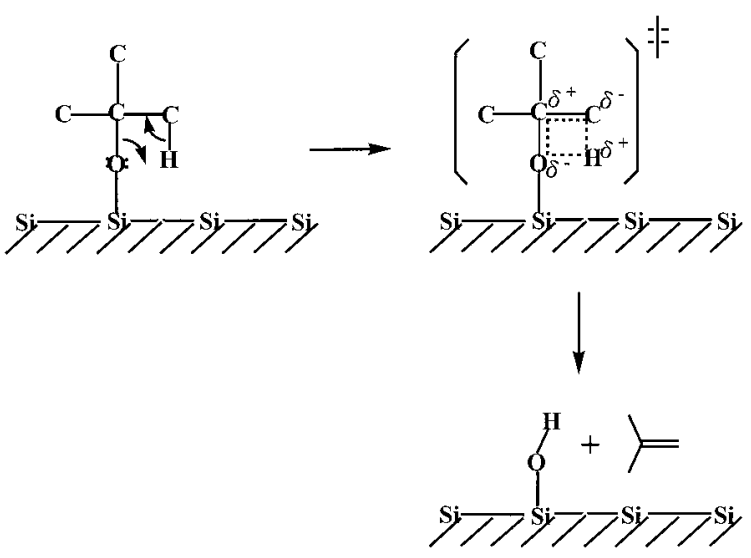

Figure 8. Proposed mechanism by which tert-butoxy fragments from tBAA produce isobutene molecules through a polar four-center transition state.

ethanol $^{52}$ and methanol, ${ }^{53}$ on silicon surfaces have shown that the alkoxy group may undergo further fragmentation to produce $\mathrm{O}, \mathrm{CO}$, and $\mathrm{CH}_{x}(x=0-3)$ species. No ethylene was identified as the reaction product. However, Pelzel et al. ${ }^{68}$ measured TPD spectra after exposure at $200 \mathrm{~K}$ of [(tert-butyl) $\mathrm{GaS}]_{4}$ to $\mathrm{Si}(100)-$ $(2 \times 1)$ and showed that the tert-butyl ligand bonded to an electronegative $\mathrm{S}$ atom could undergo a $\beta$-elimination reaction on the surface. Isobutene was the major hydrocarbon desorption product, with the distribution peaked at 280 and $500 \mathrm{~K}$, although a small amount of isobutane was also observed. Jeffries et al. ${ }^{69}$ conducted a quantitative ${ }^{1} \mathrm{H}$ NMR spectroscopy study on metalorganic chemical vapor deposition of copper metal films and copper(I) oxide from the tetrameric precursor copper(I) tertbutoxide and showed that isobutene could be produced through a four-center unimolecular reaction. In fact, results from a transition-state theoretical study ${ }^{70}$ of the gas-phase, unimolecular reactions that proceeded through a cyclic transition state showed that the activation energy for a four-center reaction to produce olefins was significantly lower for tert-butyl halides than for sec- or $n$-butyl or any other smaller hydrocarbon halides.

On the basis of these observations and the results obtained from this study, the four-center reaction mechanism depicted in Figure 8 is proposed to account for the production of isobutene from tBAA at low exposure. The mechanism involves a relatively tight four-center cyclic transition state. After the $\mathrm{tBuO}-\mathrm{CO}$ bond of tBAA is cleaved upon adsorption, the hydrogen atom in the $\beta$ position of the surface tert-butoxy species is transferred through a polar four-center transition state to the oxygen atom of the butoxy group to yield isobutene. Accordingly, the decomposition of the surface $\mathrm{tBuO}$ species can also generate hydroxyl groups on the surface. It leads to the appearance of the m/e 45 peak in the SSIMS spectrum (Figure 1), attributable to the sputter desorption of $\mathrm{SiOH}^{+}$from the surface, as well as the desorption feature above $600{ }^{\circ} \mathrm{C}$ in the m/e 44 TPD spectra (Figures 3 and 4), attributable to the sublimation of $\mathrm{SiO}$. This study, however, cannot ascertain whether the surface-induced $\mathrm{tBuO}-\mathrm{CO}$ bond cleavage and the $\beta$-hydride elimination of the surface butoxy species are stepwise reactions or proceed in concert.

4.2. tBAA Decomposition via Diketo Bonding. In addition to the decomposition of tBAA by bonding via its ester group to the surface, the surface reaction of tBAA may also proceed through bonding via its diketo moiety. The exact binding orientation of the diketo moiety of tBAA on the $\mathrm{Si}(100)$ surface is not yet clear. However, as discussed in the Introduction, results from studies on the surface adsorption of $\beta$-diketones, a class of compounds with the molecular structure similar to $\mathrm{tBAA}$, showed that the $\beta$-diketone compounds such as hexafluoroacetylacetone may bind in either a "standing-up" mode ${ }^{38,71}$ or a "lying-down" configuration ${ }^{37}$ to the surface. The tBAA may adopt the "standing-up" binding mode because of the steric hindrance of the bulky tert-butyl group. As shown in Figure 9, a surface-induced bond scission may then occur at the $\mathrm{OC}-\mathrm{CCO}$ bond of the diketo moiety. If the surface reaction proceeds through $\mathrm{tBAA}$ bonding mainly via the carboxylic keto oxygen (Figure 9a), acetaldehyde radical may be produced on the surface, contributing to the observed m/e 43 peak in the SSIMS spectrum (Figure 1). Another product is a surface bond carboxylate, which can further react on the surface to yield isobutene. For the surface reaction to proceed mainly via the aceto oxygen (Figure 9b), formic acid radical may be produced on the surface, which also would contribute to the observed $m / e 45$ peak in the SSIMS spectrum (Figure 1), along with the generation of isobutene and isopropenoxy species. It should be pointed out that the tBAA molecule may also exist as the enol tautomer, as in the case of hexafluoroacetylacetone, ${ }^{72}$ before decomposition takes place. In this case, the series of chemical species produced from the tBAA surface reaction through the "standing-up" pathway is expected to be similar to that shown in Figure 9, except that the species produced may bind to the surface through the enol, instead of the keto, oxygen.

Results from TPD studies also support this surface-induced bond scission occurring at the $\mathrm{OC}-\mathrm{CCO}$ bond in the diketo moiety of tBAA. Owing to the steric hindrance of the tert-butyl group, it is expected that the surface reaction proceeding via the aceto oxygen is more favored than via the carboxylic keto oxygen. The surface population of isopropenoxy species and formic acid should thus be higher than that of acetaldehyde radical. Because hydrogen has high surface mobility, ${ }^{51,73}$ the isopropenoxy group formed on the surface can subsequently undergo an enol-keto conversion by acquiring surface hydrogen to yield acetone. The presence of a noticeable amount of acetone on the sample surface, as shown in Figures 3 and 4, supports the bond scission of the $\mathrm{OC}-\mathrm{CCO}$ bond in tBAA when the molecule is decomposed on $\mathrm{Si}(100)$. In comparison, the electronimpact mass spectrum for acetaldehyde has main peaks at $m / e$ 29,44 , and 43 (in order of decreasing signal intensity ${ }^{45}$ ). Figure 3 reveals that, when the $\mathrm{Si}(100)$ sample is exposed to a low dose tBAA, more acetone is generated on the surface than acetaldehyde. The $\mathrm{OC}-\mathrm{CCO}$ bond of tBAA can thus be cleaved mainly by surface bonding via the aceto oxygen.

The observation of the desorption feature appearing in the temperature range between 0 and $500{ }^{\circ} \mathrm{C}$ in the $m / e$ TPD spectrum (Figure 5) also supports the decomposition mechanism, proposed in Figure 9b, by which tBAA bonds on $\mathrm{Si}(100)$ via the aceto oxygen to cause the OC-CCO bond scission. This desorption feature occurs due to the formation of carbon dioxide on the surface. According to the mechanism proposed in Figure 9b, tert-butyl formate radical is formed when tBAA decomposes through surface bonding via the aceto oxygen. Subsequent $\beta$-hydride elimination causes tert-butyl formate radical to produce formic acid radical, which in turn loses hydrogen to generate carbon dioxide. The loss of hydrogen from formic acid radical may be enhanced by the presence of other tBAA fragments on the sample surface. As shown in Figure 5, the carbon dioxide intensity between 0 and $500{ }^{\circ} \mathrm{C}$ is almost negligible at very low tBAA exposure of $0.06 \mathrm{~L}$. It increases rapidly, as compared to the acetone intensity (not shown), as the amount of tBAA fragments is increased at high exposures. 


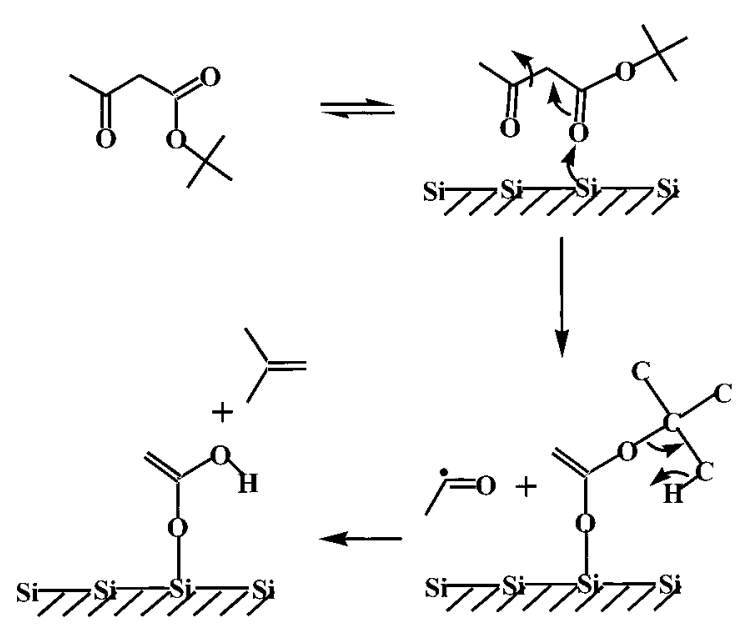

(a)
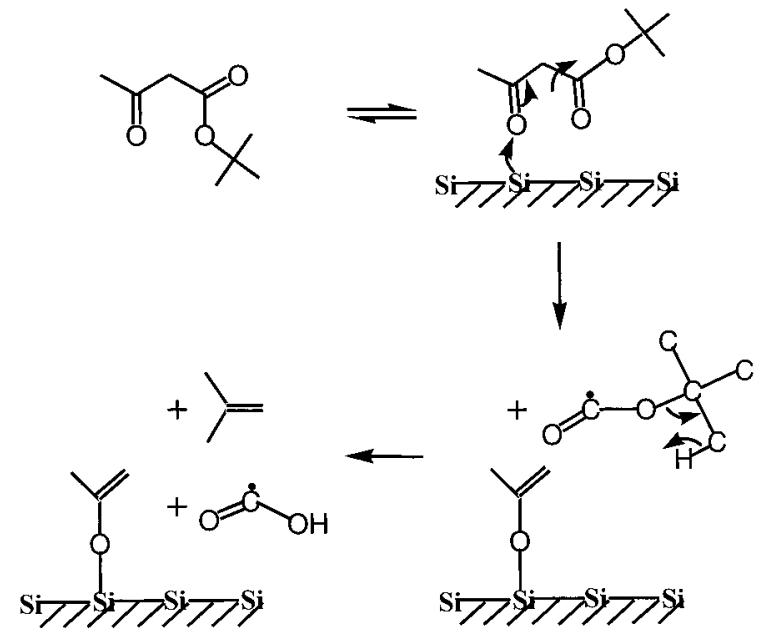

(b)

Figure 9. Proposed key surface reaction paths for tBAA adsorbed on $\mathrm{Si}(100)$ through bonding via (a) the carboxylic keto oxygen and (b) the aceto oxygen in its diketo moiety. The orientation of tBAA and fragments are meant to be suggestive only.

The acetaldehyde radical formed by the cleavage of the $\mathrm{OC}-\mathrm{CCO}$ bond through tBAA bonding via the carboxylic keto oxygen (Figure 9a) should also lead to a desorption feature around $200{ }^{\circ} \mathrm{C}$ in the m/e $44 \mathrm{TPD}$ spectrum. ${ }^{74}$ However, its desorption intensity is almost negligible compared to the $\mathrm{SiO}$ intensity above $600{ }^{\circ} \mathrm{C}$ if acetaldehyde is exposed to $\operatorname{Si}(100) .{ }^{74}$ The fact that a large m/e 44 peak is observed between 0 and $500{ }^{\circ} \mathrm{C}$ in Figure 5 thus supports the proposed tBAA decomposition mechanism in which the aceto oxygen reaction path dominates over the carboxylic keto oxygen path.

\section{Conclusions}

At tBAA exposures of $0.2 \mathrm{~L}$ or less, all tBAA molecules dissociate readily upon adsorption on the $\mathrm{Si}(100)$ surface, even at substrate temperatures as low as $-160{ }^{\circ} \mathrm{C}$. Isobutene is produced on the surface, possibly through a transfer of $\beta$-hydrogen via a relatively tight four-center cyclic transition state to the oxygen atom of the tert-butoxy fragment. Hydroxyl species are also generated on the sample surface during this process and transformed to silicon oxide at increasing substrate temperatures. An alternative pathway for yielding isobutene may involve abstraction of $\beta$-hydrogen from the surface tert-butyl fragment, either by the Si dangling bond nearby or by the $\mathrm{Si}$ atom on which the tert-butyl fragment binds.

Results of this study also suggest that the surface-induced bond scission may occur at the $\mathrm{OC}-\mathrm{CCO}$ bond of the tBAA diketo moiety at low substrate temperatures. The surface reaction proceeding mainly through tBAA bonding via the carboxylic keto oxygen of the diketo moiety produces a surface bound carboxylate, which then reacts further to generate isobutene. Acetaldehyde radical is also formed on the surface through this reaction path. For the surface reaction to proceed mainly via the aceto oxygen, formic acid radical may be produced on the surface, along with the generation of isobutene and isopropenoxy species. The dissociation of tBAA on the sample surface through bonding via the aceto oxygen is more favored than via the carboxylic keto oxygen because of the steric hindrance of the tert-butyl group. It leads to a higher surface population of acetone than acetaldehyde radical.

Results of this study of the adsorption and decomposition of tBAA on the silicon surface also demonstrate chemical principles that may be broadly representative of the $\beta$-diketonate CVD systems. It is believed that the actual decomposition process of tBAA on $\mathrm{Si}(100)$ may be more complex than what is discussed in this article. However, the assertions and hypotheses made in this work could provide a useful base from which detailed understanding may be derived.

Acknowledgment. We thank Wei-Hsiu Hung of SRRC for providing the silicon sample. This research has been supported by ROC National Science Council and the Department of Education.

\section{References and Notes}

(1) Kodas, T.; Hampden-Smith, M. J.; Eds.; The Chemistry of Metal CVD, VCH Publishers Inc.: Weinheim, Germany, 1994.

(2) Vossen, J. L.; Kern, W.; Eds., Thin Film Processes II; Academic Press: Boston, 1991.

(3) Ho, P. S.; d'Heurle, F. M.; Gangulee, A.; Electro- and ThermoTransport in Metals and Alloys; Hummel, R. E., Huntington, H. B., Eds.; American Institute of Mining, Metallurgical, and Petroleum Engineers: New York, 1977; pp 124-126.

(4) Pauleau, Y.; Fasasi, A. Y. Chem. Mater. 1991, 3, 45.

(5) Awaya, N.; Arita, Y. Jpn. J. Appl. Phys. 1991, 30, 1813.

(6) Temple, Reisman, A. J. Electrochem. Soc. 1989, 136, 3525.

(7) Kaloyeros, A. E.; Feng, A.; Garhart, J.; Brooks, K. C.; Ghosh, S. K.; Saxena, A. N.; Luehers, F. J. Electron. Mater. 1990, 19, 271.

(8) Lecohier, B.; Calpini, B.; Philippoz, J.-M.; van den Bergh, H.; Laub, D.; Buffet, P. A. J. Electrochem. Soc. 1993, 140, 789.

(9) Lai, W. G.; Xie, Y.; Griffin, G. L. J. Electrochem. Soc. 1991, 138, 3499.

(10) Kim, D.-H.; Wentorf, R. H.; Gill, W. N. J. Electrochem. Soc. 1993, $140,3273$.

(11) Awaya, N.; Arita, Y. Jpn. J. Appl. Phys. 1993, I32, 3915.

(12) Van Hemert, R. L.; Spendlove, L. B.; Sievers, R. E. J. Electrochem Soc. 1965, 112, 1123 .

(13) Huang, S. T.; Shim, I.; Lee, K. O.; Kim, K. S.; Kim, J. H.; Choi, G. J.; Cho, Y. S.; Choi, H. J. Mater. Res. J. Mater. Res. 1996, 11, 1051. (14) Zama, H.; Miyake, T.; Hattori, T. Jpn. J. Appl. Phys. Lett. 1992, 31, L588.

(15) Maruyama, T.; Ikuta, Y. J. Mater. Sci. 1993, 28, 5540.

(16) Jefferies, P. M.; Girolami, G. Chem. Mater. 1989, 1, 8.

(17) Fine, S. J.; Norman, J. A. T.; Muratore, B. A.; Dyer, P. N.; Abstracts of Papers, Fall Meeting of the Materials Research Society, 1990, E4.8.

(18) Beach, D. B.; Legoules, F. K.; Hu, C.-K. Chem. Mater. 1990, 2 , 216.

(19) Hampden-Smith, M. J.; Kodas, T. T.; Paffett, M.; Farr, J. D.; Shin, H.-K. Chem. Mater. 1990, 2, 636.

(20) Temple, D.; Reisman, A. J. Electrochem. Soc. 1989, 136, 3525.

(21) Hampden-Smith, M. J.; Kodas, T. T. Polyhedron 1995, 14, 699.

(22) Reynolds, S. K.; Smart, C. J.; Baran, E. F. Appl. Phys. Lett. 1991, $59,2332$.

(23) Stumm, T. H.; van den Bergh, H. Mater. Sci. Eng. 1994, B23, 48.

(24) Voss, S.; Gandikota, S.; Chen, L.-Y.; Tao, R.; Cong, D.; Duboust,

A.; Yoshida, N.; Ramaswami, S. Microelectron. Eng. 2000, 50, 501. 
(25) Kroger, R.; Eizenberg, M.; Cong, D.; Yoshida, N.; Chen, L. Y.; Ramaswami, S.; Carl, D. Microelectron. Eng. 2000, 50, 375.

(26) Goswami, J.; Raghunathan, L.; Devi, A.; Shivashankar, S. A.; Chandrasekaran, S. J. Mater. Sci. Lett. 1996, 15, 573.

(27) Devi, A.; Shivashankar, S. A. J. Mater. Sci. Lett. 1998, 17, 367.

(28) Devi, A.; Goswami, J.; Lakshmi, R.; Shivashankar, S. A.; Chandrasekaran, S. J. Mater. Res. 1998, 13, 687.

(29) Zahidi, E.; Castonguay, M.; McBreen, P. H. J. Phys. Chem. 1995, 99, 17906.

(30) Barteau, M. A.; Bowker, M.; Madix, R. J. Surf. Sci. 1980, 94303.

(31) Schwaner, A. L.; Fieberg, J. E.; White, J. M. J. Phys. Chem. 1997, B101, 11112 .

(32) Schwaner, A. L.; White, J. M. J. Phys. Chem. 1997, B101, 11119.

(33) Zahidi, E.; Castonguay, M.; McBreen, P. H. J. Am. Chem. Soc 1994, $116,5847$.

(34) Sexton, B. A.; Hughes, A. E.; Avery, N. R. Surf. Sci. 1985, 155 366.

(35) Sexton, B. A.; Hughes, A. E.; Avery, N. R. Appl. Surf. Sci. 1985, 22/23, 404.

(36) Worley, S. D.; Yates, J. T., Jr. J. Catal. 1977, 48, 395.

(37) Parmeter, J. E. J. Phys. Chem. 1993, 97, 1530.

(38) Girolami, G. S.; Jeffries, P. M.; Dubois, L. H. J. Am. Chem. Soc. 1993, $115,1015$.

(39) Nigg, H. L.; Masel, R. I. Surface Sci. 1998, 409, 428.

(40) Ishizaka, A.; Shiraki, Y. J. Electrochem. Soc. 1985, 133, 666

(41) Bozso, F.; Yates, J. T., Jr.; Choyke, W. J.; Muehlhoff, L. J. Appl.

Phys. 1985, 57, 2771.

(42) Chang, C.-C.; Hsieh, J.-Y. Phys. Rev. 1998, B57, 57.

(43) Garrison, B. J. J. Am. Chem. Soc. 1980, 102, 6553.

(44) Wandass, J. H.; Schmitt, R. L.; Gardella, J. A., Jr. Appl. Surf. Sci. 1989, 40,85 .

(45) Stenhagen, E.; Abrahamsson, S.; McLafferty, F. W., Eds.; Atlas of Mass Spectral Data; Interscience Publishers: New York.

(46) Ibach, H.; Bruchmann, H. D.; Wagner, H. Appl. Phys. 1982, A29, 113.

(47) Schulze, R. K.; Evans, J. F. Appl. Surf. Sci. 1994, 81, 449.

(48) Joyce, B. A. Surf. Sci. 1973, 35, 1.

(49) Walczak, M. M.; Leavitt, P. K.; Thiel, P. A. J. Am. Chem. Soc. 1987, 109, 5621.

(50) Hashizume, T.; Hamers, R. J.; Demuth, J. E.; K. Markert. Sakurai,

T. J. Vac. Sci. Technol. 1990, A8, 249.
(51) Casaletto, M. P.; Zanoni, R.; Carbone, M.; Piancastelli, M. N.; Aballe, L.; Weiss, K.; Horn, K. Surf. Sci. 2000, 447, 237.

(52) Carbone, M.; Piancastelli, M. N.; Paggel, J. J.; Chr. Weindel, Horn, K. Surf. Sci. 1998, 412/413, 441

(53) Carbone, M.; Zanoni, R.; Piancastelli, M. N.; Comtet, G.; Dujardin, G.; Hellner, L. Surf. Sci. 1996, 352-354, 391.

(54) Kaneda, G.; Murata, J.; Takeuchi, T.; Suzuki, Y.; Sanada, N.; Fukuda, Y. Appl. Surf. Sci. 1997, 113/114, 546.

(55) Rudkevich, E.; Saulys, D.; Gains, D.; Kuech, T. F.; McCaughan,

L. Surf. Sci. 1997, 383, 69.

(56) Rueter, M. A.; Vohs, J. M. Surf. Sci. 1992, $262,42$.

(57) Darlington, B.; Foster, M.; Campion, A. Surf. Sci. 1994, 304, L407.

(58) Schmidt, J.; Ch. Stuhlmann, Ibach, H. Surf. Sci. 1994, 302, 10.

(59) Du, W.; Keeling, L. A.; Greenlief, C. M. J. Vac. Sci. Technol. 1994, A12 2281

(60) Lin, R.; Gow, T. R.; Backman, A. L.; Cadwell, L. A.; Lee, F.; Masel, R. I. J. Vac. Sci. Technol. 1989, B7, 725 .

(61) Bent, B. E.; Nuzzo, R. G.; Dubois, L. H. J. Vac. Sci. Technol. 1988 A6, 1920 .

(62) Bent, B. E.; Nuzzo, R. G.; Dubois, L. H. J. Am. Chem. Soc. 1989, $111,1634$.

(63) Dillon, A. C.; Robinson, M. B.; Han, M. Y.; George, S. M. Mater. Res. Soc. Symp. Proc. 1991, 222, 213.

(64) Keeling, L. A.; Chen, L.; Greenlief, C. M.; Mahajan, A.; Bonser, D. Chem. Phys. Lett. 1994, 217, 136.

(65) Rueter, M. A.; Vohs, J. M. J. Vac. Sci. Technol. 1991, A9, 2916

(66) Chen, J. G.; Beebe, T. P., Jr.; Crowell, J. E.; Yates, J. T., Jr. J. Am. Chem. Soc. 1987, 109, 1726.

(67) Egger, K. W. J. Am. Chem. Soc. 1969, 91, 2867.

(68) Pelzel, R. I.; Hopcus, A. B.; Owen, J. H. G.; Nosho, B. Z.; Weinberg, W. H. J. Vac. Sci. Technol. 1998, B16, 2399.

(69) Jeffries, P. M.; Dubois, L. H.; Girolami, G. S. Chem. Mater. 1992 4, 1169.

(70) O’Neal, H. E.; Benson, S. W. J. Phys. Chem. 1967, 71, 2903.

(71) Girolami, G. S.; Nuzzo, R. G.; Lin, W. J. Am. Chem. Soc. 1996 118,5988

(72) Andreassen, A. L.; Zebelman, D.; Bauer, S. H. J. Am. Chem. Soc. 1971, 93, 1148

(73) Briggs, G. A. D.; Fisher, A. J. Surf. Sci. Rep. 1999, 33, 1.

(74) Armstrong, J. L.; White, J. M.; Langell, M. J. Vac. Sci. Technol. 1997, A15 1146. 